*Doutora em Direito Público e Evolução Social. Processo Penal (UNESA/2014). Estágio PósDoutoral em Democracia e Direitos Humanos na Universidade de Coimbra (Portugal). Mestre em Ciências Penais -Criminologia (UCAM/2003). Diplomada em Direito Internacional Humanitário pelo International Institute of humanitarian Law. (IIHL- 2014). Especialista em Direito Penal Militar (UCAM). Possui graduação em Direito (USU/1993). Tem experiência na área do Direito Penal com ênfase no Processo Penal, Criminologia e Direito Internacional Humanitário, tendo como base de pesquisa a filosofia contemporânea de Jürgen Habermas. Diretora de Ensino, Pesquisa e Eventos da Fundação Instituto Brasileiro de Direito Militar e Humanitário IBDMH; Advogada especializada na área Criminal. Professora de Direito e Processo Penal IBMEC. E-mail: claudiaaguyar@uol.com.br

\section{Dos Totens Às Vestes Talares: \\ Os Atores Processuais (Des)Conhecem o Que é DEMOCRACIA?}

\author{
Of the Totes to the Toga: \\ Do the Processing Actors Know What is Democracy?
}

Claudia Aguiar Silva Britto*

Como citar: BRITTO, Cláudia Aguiar Silva. Dos totens às vestes talares: os atores processuais (des)conhecem o que é democracia?. Revista do Direito Público, Londrina, v. 15, n. 1, p. 174-192, abr. 2020. DOI: 10.5433/24157-108104-1.2020v15 n1p. 174. ISSN: 1980-511X

Resumo: O presente artigo tem por escopo apresentar algumas perspectivas pragmáticas a respeito dos possíveis (des)conhecimentos, por parte dos atores processuais, no que diz respeito ao sentido de democracia no universo da práxis jurídico-penal, seus papéis e responsabilidades diante desse cenário, como esses fenômenos podem ser percebidos no ambiente forense cotidiano e, de uma forma bastante própria, no Brasil. Por fim, o que eles acarretam ou acarretariam para o futuro da democracia do país. Para tanto, como referencial fático, considerações realistas da dinâmica do Processo Penal são apresentadas. Como referencial teórico, as digressões estão calcadas na filosofia contemporânea, especificamente ligadas à democracia e ação comunicativa de Habermas.

Palavras-chave: Democracia. Responsabilidades. Ação comunicativa. Processo penal.

Abstract: This paperaims to present some pragmatic perspectives concerning the possible knowledge from procedural actors regarding the direction of democracy in the world of the criminal legal practice, their roles and responsibilities towards this matter, as these phenomena can be noticed in our everyday forensic environment, and in such a unique way in Brazil. Finally, this paper investigates what it would do to the future of democracy in this country. Furthermore, as a phatic referential, realistic considerations of the dynamics of the Criminal Procedure are presented. With a theoretical reference, digressions utilize contemporary philosophy, specifically linked to Habermas' democracy and communicative action. 
Keywords: Democracy; Responsibilities; Communicative Action; Criminal Procedure. 


\section{INTRODUÇÃO}

Neste trabalho serão abordados, de maneira inicial e muito breve, as raízes ritualísticas e o desenvolvimento dos grupos para a construção da democracia e as diferentes "roupagens" e "linguagens" que demarcariam o espaço do outro até a era atual. Após, serão revisados alguns dados filosóficos sobre as experiências democráticas ligadas à linguagem. Na terceira parte do texto, procura-se enfocar a problemática no funcionalismo da justiça e os erros judiciários no Estado de Direito, apresentando algumas circunstâncias concretas aliadas às reflexões teóricas em torno do assunto, sobretudo a partir da análise das convenções internacionais de direitos humanos, cuja perspectiva racional e normativa está alicerçada na ideia de um processo justo. A quarta e última parte foi destinada à práxis jurídica e à paralaxe cognitiva, a fim de demonstrar alguns sorvedouros que merecem maior atenção dentro do sistema de administração da justiça. Como referencial fático, considerações realistas da dinâmica do Processo Penal serão apresentadas. Como referencial teórico, o texto está calcado na filosofia, especificamente ligada à democracia e o agir comunicativo de Habermas.

\section{INTRODUÇÃO HISTÓRICA: TOTENS, CLASSES E CLÃS NA DIVISÃO DO PODER}

As raízes históricas da humanidade explicavam o universo em bases práticas. A crença na existência de um elo místico e próximo entre os seres humanos e os elementos da natureza, como as plantas e os animais, demarcava o ponto de partida para compreender as origens e as metas da vida, seus propósitos e suas interações. As formas de noção do "Eu" (MAUSS, 2007, p. 382). ${ }^{1}$ É nesse sentido que Mauss (2007, p. 371) afirma que nunca houve ser humano que não tenha tido o senso, não apenas de seu corpo, mas também de sua individualidade espiritual e corporal ao mesmo tempo. Porém, de que maneira as numerosas sociedades foram elaborando lentamente o conceito que os homens das diversas épocas criaram a seu próprio respeito? Nos índios Pueblos de Zuñi, a existência de um número determinado de prenomes por clã definiria o papel exato que cada um desempenharia. Qualquer totem, por exemplo, o braço direito ou a perna de um animal, corresponderia ao norte e seria o primeiro em honra do clã; então, o nome referente a outro membro, como a perna ou o braço esquerdo e seus poderes pertenceria ao oeste e seria o segundo em honra, e assim sucessivamente. Pelos estudos desenvolvidos a partir dos povos agora localizados no noroeste americano, Mauss (2007) afirma ser possível ver muito nitidamente como, a partir das classes e dos clãs, ordenam-se as "pessoas humanas" e como, a partir dessas, ordenam-se os gestos dos atores num drama. Aqui, todos os seres humanos são teoricamente todos os homens livres. Mas, desta vez, o drama é mais do que estético. É religioso e, ao mesmo tempo,

1 O clã, de modo algum, é representado como um ser inteiramente impessoal. Coletivo, o totem é representado pela espécie animal, e não pelos indivíduos - homem de um lado, animais de outro. Os índios Pueblos de Zuñi pertencem à divisão ocidental do sudoeste dos Estados Unidos. "A noção de pessoa, do indivíduo confundido com seu clã, mas já destacado dele no cerimonial pela máscara, por seu título, sua posição, seu papel, sua propriedade, sua sobrevivência e seu reaparecimento na terra num de seus descendentes dotados das mesmas posições, prenomes, títulos, direitos e funções.” (MAUSS, 2007, p. 382). 
cósmico, mitológico, social e pessoal. Os fatos mais primitivos estudados pelo antropólogo francês dizem respeito à Austrália, onde o clã, de modo algum, é representado como um ser impessoal, coletivo. Mas entre uma pintura facial ou corporal e uma vestimenta e uma máscara, há somente uma diferença de grau, nenhuma de função. A presença ou ausência da máscara, ressalta o autor, são antes traços de arbitrariedade social, histórica e cultural, mais do que traços fundamentais. Com um giro topográfico é de se registrar que a Índia é a mais antiga das civilizações que adquiriram a noção do indivíduo, de sua consciência, do "Eu".

Por muito tempo, a humanidade passou acreditando que tudo sofria a interferência divina. As máscaras, as vestimentas, os rituais e os símbolos totêmicos, ora significavam poder, ora submissão à vontade mística. As dúvidas sobre todas as causas do universo começaram a surgir. À medida que a percepção humana se intrigava com os fenômenos e com o fato de que estes não se manifestavam em razão de forças "superiores" ou sobrenaturais, o trabalho humano passou a caminhar em outra trilha, a filosófica, procurando conhecer quais as leis que regeriam o mundo. É dizer: a filosofia quis romper com esse estado de coisas etéreas respondendo que existiam leis naturais regendo o universo e que o único caminho era conhecê-las.

O reconhecimento dos esforços dos filósofos gregos na Antiguidade, ao concluírem que os deuses eram "invenção humana com finalidades políticas e que o povo não podia ficar sujeito a governantes que decidiam por livre vontade", possibilita-nos perceber o longo e árduo caminhar em torno do conhecimento do sentido da democracia. A história conta que o "rito de passagem" da divindade à metafísica filosofal, especificamente quanto ao desenvolvimento no âmbito das sociedades e da política, não foi estabelecido em águas calmas, na medida em que se entendia que na política e na sociedade existiam interlocuções que permitiriam a algumas pessoas terem poderes mais amplos que as demais (BRITTO, 2014, p. 82).

Circunstância importante, destacada por Mauss (2007), quanto à construção da cidadania na Roma Antiga, onde a condição de que todos os homens livres fossem cidadãos romanos, todos tiveram assim a persona civil. Alguns se tornaram personas religiosas; algumas máscaras e rituais permaneceram ligados a algumas famílias privilegiadas dos colégios religiosos (MAUSS, 2007, p. 389). ${ }^{2}$ Mas a partir da linguagem corporal à linguagem da fala, entre consensos e dissensões, os indivíduos construíam aquilo que, mais tarde, foi cunhado de democracia.

Não é de se estranhar que, nos longevos períodos da civilização humana, a palavra sempre representou a força motriz que determinava e conduzia a sociedade, seja unindo-a, popularizando-a ou até mesmo evitando conflitos de interesses. A palavra tinha grande valor na resolução dos assuntos, muitas vezes, mesmo com sacrifício do acerto, da justiça, da prudência (CROISSET apud FRANCA, 1936, p. 19).

Nas civilizações antigas, a palavra utilizada nos tribunais, nas decisões submetidas às cortes julgadoras, possuía força incomum. Nos tribunais atenienses, onde se debatiam negócios públicos, todos os meios injuriosos eram utilizados para desestabilizar o adversário. No Fórum

2 Paralelamente à palavra persona, personagem artificial, máscara e papel de comédia e de tragédia representando o embuste, a hipocrisia - o estranho ao "Eu" - prosseguia seu caminho. Mas o caráter pessoal do direito estava fundado e persona também havia se tornado sinônimo da verdadeira natureza do indivíduo. 
Romano, os discursos eloquentes e até desrespeitosos denunciavam que a palavra já não possuía a força do consenso, mas era propulsora de conflitos. Entretanto, em nossa era, a linguagem passou a constituir a "ferramenta indispensável por meio da qual as interações se interligam e as formas de vida se estruturam." HABERMAS, 2003, p. 20). Os mecanismos postos à disposição das sociedades menos remotas propiciaram um ambiente mais dialogal no qual passaríamos a buscar "processos de entendimentos não violentos".

É importante destacar que os fatos ora demarcados neste breve histórico tiveram como base uma rápida análise das linguagens sentidas no âmbito da civilização ocidental, lugar onde os discursos cosmológicos se transmutam para os discursos políticos. A partir daí se estabelece um novo período denominado antropológico, que irá coincidir com o ponto central da democracia greco-romana.

\section{AS FORMULAÇÕES DEMOCRÁTICAS ATRAVÉS DA LINGUAGEM}

A proposta do presente ensaio não tem o objetivo de analisar o vasto caminho histórico para a democracia, mas apresentar alguns elementos a respeito dos possíveis (des)conhecimentos dos personagens processuais em relação ao sentido democrático de seus papéis atuais no cenário jurídico. E como esses fenômenos podem ser percebidos no ambiente forense cotidiano e, de uma forma bastante própria, no Brasil.

Para tanto, as categorias da linguagem alcançadas por Habermas oferecem um primoroso estudo. A essência é garantir a gênese da democracia do direito. Ainda que seus estudos estejam relacionados especificamente às esferas germânica e estadunidense, a proposta comunicacional do filósofo não parece incompatibilizar-se com a perspectiva de uma teoria da constituição dirigente, cuja função é propor um plano realizável para a sociedade, melhoria das condições econômicas e bem estar para todos. Idealiza-se um programa racional que dê conta, não só de garantir os princípios jurídicos, mas efetivá-los também. Daí porque a Constituinte Brasileira de 1988, definidora de normas programáticas, é reconhecida como dirigente. Mas nessa perspectiva, como assegurar a autonomia dos cidadãos diante do problema da exclusão? (NASCIMENTO, 2005, p. 421-437). Como superar os paradigmas anteriores para que esse programa futuro para a sociedade possa realmente efetivar-se, sobretudo no âmbito do funcionamento da justiça? Como assegurar a efetividade dos direitos fundamentais dos acusados, qualquer que seja o réu? Estas são algumas perguntas que permanecem no plano teórico, mas que devem vir à tona no plano prático.

A partir da profundidade das reflexões de Jürgen Habermas, especialmente no que se refere à sua visão de democracia do século XXI, é possível compreender como a comunicação é parte fundamental na construção democrática. A proposta discursiva de Habermas encontra apoio, mas também dissensões. A divergência flutua tanto sob o argumento de que a teoria procedimentalista Habermasiana desconsideraria as exigências substantivas para o real exercício de direitos fundamentais, bem como o argumento de que "não haveria propriamente uma teoria 
da constituição vista como fenômeno universal." (OLIVEIRA, 2011, s/p). ${ }^{3}$ Nascimento (2005) diz que o debate brasileiro do pensamento inspirado no filósofo costuma ressentir-se de certo reducionismo, ao limitar a visão procedimental da ética discursiva a uma concepção sobre a função da jurisdição constitucional concentrada.

É inspiradora a desenvoltura de Habermas na construção da sua filosofia comunicacional. Para superar as suas próprias dificuldades comunicativas, decorrentes de uma fenda labial e rejeições sociais, o filósofo decidiu se aprofundar nos estudos da linguagem como forma de "acesso ao mundo". Todos os seus trabalhos passaram a receber a face da razão discursiva. E é nesse contexto que "interpretar e criticar o modelo institucional de forma a abrir as fronteiras a todos e também justamente àqueles que são estranhos um ao outro - e querem continuar sendo" (HABERMAS, 2007, p. 8) sugere o ponto firme da teoria comunicacional de Habermas. O filósofo inclui o "Outro" como partícipe da linguagem. Habermas não sugere um novo ideal democrático; ele procura demonstrar o que já está posto nas atuais instituições políticas de alguns organismos internacionais.

A inspiração de Habermas, de fonte kantiana, baseia-se na interpenetração do livre arbítrio e da razão prática que permitiria conceber a comunidade moral como uma comunidade abrangente que faz suas próprias leis, isto é, "uma comunidade de indivíduos livres e iguais que se sentem obrigados a tratar uns aos outros como fins em si mesmos.” (HABERMAS, 2007b, p. 17). Sob a ótica do constitucionalismo contemporâneo, essa ideia fornecida por Habermas robustece o argumento de que tratamentos diferenciados aos personagens processuais não podem mais subsistir no cenário jurídico criminal (GARCIA AMADO, 2003).

Nos atos de fala, dentro do círculo comunicacional habermasiano, são concebidas quatro bases para o consenso: as pretensões de validade se iniciam a partir de uma fala inteligível, clara, acessível. Em sequência, o conteúdo que se quer transmitir deve ser verossímil. Em terceiro plano, as intenções devem ser sinceras. E, quarto e último ponto, a manifestação do falante deve estar pautada nas regras e nos valores vigentes. Embora a linguagem tenha função especial no consenso, ela pode ser desvirtuada dentro da "ação estratégica" quando for manipulada e utilizada para dominação. Daí porque essa ideia do discurso processual deve estar livre de dominação.

$\mathrm{Na}$ dinâmica do processo no modelo adversarial system, argumentos e contra-argumentos devem ser postos e propostos pelas partes com base nas pressuposições da comunicação. Neste modelo, o juiz criminal não controla o processo, não é gestor da produção probatória. O julgador permanece neutro e passivo diante das provas colhidas e produzidas pelas partes.

Analisando a teoria da argumentação, Bal (1996, p. 86-87, tradução nossa) sublinha que não importa o número de participantes do diálogo, mas se estão ou não engajados na tarefa de transmitir argumentos claros e abrangentes:

3 “[...] As objeções de Lenio Streck, em Jurisdição constitucional e hermenêutica, vão desde a simples afirmação de que a teoria habermasiana não se apresentaria adequada à realidade brasileira, de terceiro mundo, já que desenvolvida no primeiro mundo, até a objeção mais profunda, segundo a qual não haveria propriamente uma Teoria da Constituição para o constitucionalismo visto como fenômeno universal, já que assim se estaria desconsiderando, mais uma vez, a específica realidade social, econômica e política de Estados que não teriam vencido as mesmas etapas históricas europeias e norte-americanas. [...]" (OLIVEIRA, 2011). 
[...] A tarefa de trabalhar um argumento pode ser feita por uma ou algumas pessoas. Dessa forma nós distinguimos entre argumentos individuais e coletivos. Essa distinção não depende do número de participantes na interação verbal, mas se uma ou algumas estão engajadas na solução da tarefa. No curso de argumentação coletiva as pessoas envolvidas podem defender o mesmo ou diferentes respostas à questão. Dessa forma nos distinguimos entre estágios antagônicos e unânimes das argumentações. Uma argumentação pode ser privada, tal como disputas espontâneas durante uma festa, ou pública, tal como jurídica, política, ou científica, que lida com numerosas restrições institucionais na tomada de posições, questões admissíveis, candidatos aptos à argumentação [...]. ${ }^{4}$

No trâmite de um processo criminal, a força dos argumentos tem relevância para o consenso.

\section{FUNCIONALISMO E ERROS JUDICIÁRIOS NO ESTADO DEMOCRÁTICO}

As mudanças sociais, sobretudo as relacionadas à aplicação das normas processuais na justiça penal, firmaram o princípio acusatório e público. Fruto de uma conquista do liberalismo, que o tornou livre das amarras do inquisitorialismo, o sistema acusatório foi abraçado por várias Constituições.

O direito a um processo justo (right to a fair trial) constitui um condição essencial do Estado democrático e do sistema acusatório, reforçado por correntes liberais as quais alimentaram a defesa dos direitos humanos nos últimos séculos. Esse direito pressupõe uma paridade de "armas". Atores processuais devem receber o mesmo tratamento, igualdade de condições e oportunidades na defesa de seus argumentos e contra-argumentos. Entretanto, nem sempre se visualiza a igualdade de tratamento no ambiente do processo criminal. Daí a expressão de Hassemer quando se refere ao processo penal como uma "cerimônia perigosa", onde os atores processuais e suas vestes talares, que remontam às máscaras rituais da civilização medieval, formam seus clãs aparelhados contra o "estranho".

Em diferentes países e nas últimas décadas, os erros judiciários têm sido objeto incessante de estudo e reflexão. A justiça canadense, por exemplo, vem estudando com afinco os erros de sua Corte, os quais demandam condenações e prisões injustificadas, bem como diferentes tratamentos em torno do acusado (CAMPBELL; DENOV, 2008). Nos últimos anos o problema de condenações injustas se tornou uma realidade aceita na maioria dos países. Casos que são objeto de extensa cobertura midiática, não só são importantes para chamar a atenção sobre os efeitos nocivos das

4 Cf. "[...] The task of working out an argument may be undertaken by one or by several people; accordingly, we distinguish between individual and collective argumentations; this distinction does not hinge on the number of participants in verbal interaction, but on whether one or several people are engaged in solving the task. In the course of a collective argumentation, the people engaged may advocate the same or different answers to the question; accordingly, we distinguish between unanimous and antagonistic stages of argumentations. An argumentation may be private, such as a spontaneous disputes during a party, or public, such as juridical, political or scientific ones, which underly numerous institutional restrictions on turn-taking, admissible questions, admissible candidates for arguments, etc.[...].” (BAL, 1996, p. 86-87). 
injustas condenações, mas tambem para identificar falhas nos processos de justiça criminal. As pesquisas têm demonstrado vários fatores para as condenações e encarceramentos injustificados, proveneintes de erros judiciários. Em relatório publicado pelo Ministério da Justiça do Canadá sobre a prevenção de erros judiciários (CANADA, 2005), uma série completa de recomendações mostra o grau de práticas equivocadas, com o fim de evitar a reiteração de erros. O relatório descreve atividades preventivas projetadas para atender aos fatores que contribuem regularente para condenções injustas, inclusive os relacionados a ideias preconcebidas, depoimentos de testemunhas, falsas confissões etc. Essas recomendações de política foram consideradas como um primeiro passo importante no sentido de um processo mais transparente e justo de justiça criminal. O entendimento é que a partir disso se deve considerar de forma mais aprofundada as modalidades de implementação dessas recomendações em práticas cotidianas na justiça criminal, bem como o seu impacto sobre as pessoas presas injustamente. Em razão do impacto profundo e duradouro de natureza psicológica, social e econômica proveniente de condenações injustas (condenados e respectivas famílias), a justiça canadense tem procurado dar maior atenção às necessidades de prevenção e satisfação às pessoas envolvidas, fator essencial para garantir justiça para todos.

Como resultado de uma investigação na França sobre o sistema judicial, em 1997 e 2001, estudos de opinião foram divulgados e demonstraram que a instituição judiciária daquele país sofre déficit de confiança por parte da população. Em maio de 2008, por iniciativa do Conselho Superior da Magistratura, nova pesquisa foi realizada, mas revelou pouca evolução no quadro de confiança da população no Poder judiciário. Entender as razões da crise de confiabilidade, ouvir as críticas e de onde elas se originam parece ser o objetivo adotado pela justiça francesa desde então (CONSEIL SUPÉRIEUR DE LA MAGISTRATURE, 2008). Uma das causas apontadas nas pesquisas promovidas refere-se à dificuldade da opinião pública em compreender corretamente a organização judiciária. Falta clareza.

A outra questão está situada no fato de que "a justiça não é a mesma para todos, é injusta e não se adapta à evolução social". Ou seja: a justiça francesa se depara com um verdadeiro problema de comunicação.

A falta de clareza das decisões, bem como a falta de compreensão sobre o funcionamento da justiça são fatores que incomodam significativamente os franceses. ${ }^{5}$

Garapon, jurista francês, observa que: entre a "idealização e a diabolização", a justiça é o último lugar de visibilidade da democracia. La justice étant un des derniers lieux de visibilité de la démocratie.

E o simbolismo da ordem, diz Garapon, é construído a partir da sala de audiência,

[...] Recriando e reorganizando um mundo, como fazem no interior de uma sala de audiências, os homens repetem o ato inaugural da cultura. Organizam o caos e lhes dão uma estrutura, forma e normas. Essa relação entre a forma e a norma é essencial para a experiência da justiça. O aprendizado da norma no processo começa através da visibilidade da sala de audiência. Ao organizar o espaço 
judicial, o grupo social representa o ato de insubordinação em relação ao destino e à morte $[\ldots]^{6}$ (GARAPON, 2001, p. 44, tradução nossa).

Essa sacralização da ordem, explica o jurista, compreende a relação que justifica o processo: "ela exorciza a vulnerabilidade do grupo social que a infração ou conflito revela" (GARAPON, 2001, p. 44, tradução livre). ${ }^{7}$ Estava certo Garapon quando bem descreveu a justiça francesa e também Hassemer, quando classificou de "cerimônia perigosa" a ritualística judicial.

Em muitos episódios a "beligerância" processual se faz presente:

[...] Inicialmente representada pela estrutura física de caráter dominatório das salas de audiências, onde a relação triangular se escamoteia diante do paralelismo cênico, porém real, entre Estado-juiz e Estado-acusação. [...] (BRITTO, 2014, p. 64)

Um ao lado do outro: julgador e acusador. E a defesa distante e estrategicamente posta em posição inferior à cena dominatória. Todo simbolismo cênico alcança até mesmo o comportamento, as atitudes de linguagem manifestadas pelos representantes dos órgãos do Estado.

O formalismo processual, do modo como é posto e empregado, tão observado nas investigações antropológicas e sociológicas, evidentemente contribui para prolongar a arbitrariedade e perenizar a desconfiança nos ambientes judiciais.

Sobre a libertação de presos inocentes nos EUA, a organização National Registry of Exonerations (2014) (Universidade de Michigan), concluiu, em 2013, que das 87 condenações equivocadas, quase um terço dos fatos imputados não existiram. Dentro desse cômputo, $17 \%$ dos erros judiciários ocorreram em razão de confissões falsas precedidas de coação (MELO, 2014).

No Brasil, quase setecentas mil pessoas cumprem pena no sistema carcerário; cerca de $30 \%$ dos presos esperam julgamento. Os erros judiciários são muitos, mas não há números ou estatísticas oficiais. No episódio relacionado à chacina de Vigário Geral, no Rio de Janeiro, um dos acusados foi impronunciado por manifesta inexistência de autoria, mas permaneceu 741 dias preso cautelarmente, em expressivo excesso de prazo que se traduziu em 10 vezes mais do que autoriza a lei processual penal. ${ }^{8} \mathrm{O}$ art. $5^{\circ}$ inciso LXXV da Constituição brasileira dispõe que o Estado indenizará o condenado por erro judiciário, assim como aquele que ficar preso além do tempo fixado na sentença. Neste caso, o STJ, por maioria, concedeu ao recorrente, em decorrência do sofrimento e da humilhação impingidos, indenização por responsabilidade objetiva do Estado, porquanto demonstrada causalidade "faute du service".

6 Cf. Garapon (2001, p. 43): [...] En recréantun monde, en réorganisant le monde, comme ils le font dans une sale d'audience, les homes répètent l'acte inaugural de la culture. Ils réorganisent le chaos en lui donnant une structure, des formes et des normes. Cette relation entre la forme et la norme est essencielle à l éxperience de la justice, $L$ 'appretissage de la norme vécue dans le procés commence par la vision de la sale d'audience. Em organisant ainsi $l^{\prime}$ espace judiciaire, le groupe social pose um acte d'i nsubordination à l égard de la fatalité et de la morte. [...

] [ [...] la salle dáudience, òu chacun passe sous le controle drect des professionels, à commencer par les avocats. Léspace reforce leur statut aux yeux du cliente [...]

7 Cf. Garapon (2001, p. 44) [...] Cette sacralisation de l'ordre esta à comprendre en relation avec l' infraction qui a justifié le procès: ele exorcise la vulnérabilité du groupe social que l'infraction ou le conflit ont revélé”.[...].

8 RE-STF 872.630 (2006.0132.523-1) 
O processo legal, especialmente o criminal, ainda deixa a desejar em vários sentidos, especialmente naquele no qual se busca uma condição ideal de fala. Ademais, a necessidade premente de se finalizar rápido o procedimento gera erros, equívocos dos mais variados e, muitas vezes, teratológicos. ${ }^{9}$

[...] Como instituição social e mais especificamente como instituição jurídica, o processo penal tem funções que também precisa cumprir a custo de elementos comunicativos; se eles não as cumprem, então o sistema social corre o risco de que continue a não cumprir as funções, ou até mesmo de que elas sejam assumidas e efetivadas por outros representantes (por exemplo, por particulares), uma vez que elas representam necessidades fundamentais e mais amplas da nossa cultura jurídica. [...] (HASSEMER, 2005, p. 189-190).

Não menos problemática é a questão do imediatismo, a pressão para se alcançar uma decisão dentro de um curto espaço de tempo. Sem dúvida, uma duração razoável do processo criminal fortalece a ideia do processo justo. A resposta estatal deve ser dada dentro do tempo adequado para que o regular processo se desenvolva até o final, evitando incertezas e inseguranças. Entretanto, não se pode confundir duração razoável (art. $5^{\circ}$ LXXVIII) com imediatismo ou "acelerador" de feitos processuais. O processo penal precisa de um tempo. O tempo do assentamento das provas, o tempo dos argumentos e contra-argumentos, das aceitações e das dissensões. O tempo do processo penal não é equivalente a nenhum outro mecanismo processual. Isso porque há uma real exigência no que diz respeito à maturação da prova penal. $\mathrm{O}$ conjunto probatório pujante acerca dos fatos e da autoria só advém a partir de um procedimento dialético escorreito, insofismável.

Segundo a filosofia comunicacional, a linguagem comum é resultado de uma interação entre sujeitos capazes de falar e agir e que se comunicam com o objetivo de se entenderem. Mas alcançar um entendimento é um conceito normativo que supõe não coercitividade.

Assim, dentro da perspectiva do processo penal, pode-se extrair que os participantes precisam explorar suas competências argumentativas, circunstância indissociável ao processo comunicacional. Sem esse nivelamento de habilidade de debate, de argumentos, de tempo igual e suficiente entre os envolvidos, o consenso não acontece. E se o consenso não ocorre, pode significar que a duração do processo não foi razoável ou satisfatória.

[...] Podemos falar em consenso racional na medida em que nossa convicção tenha sido realmente alcançada de maneira comunitária. Daí poder parecer que todo consenso racional tenha que ser também verdadeiro. Mas ele é visto deste modo só na perspectiva interna dos indivíduos respectivamente envolvidos; o fato de eu ter razões para dar meu consentimento quer dizer que há uma pretensão de validade que julgo verdadeira; [...] (WELMER apud DUSSEL, 2012, p. 204).

Desse modo, é curial que o processo penal, como "cerimônia perigosa", deve privar o

9 Cf.: 2012.08.03. www.justice.gc.ca. canada. (http://www.justice.gc.ca/fra/pr-rp/jr/jr13/p5a.html,). «Aucours des dernièr esannées, leux. 
juiz, o Ministério Público e a opinião pública da liberdade de disposição. Não se pode permitir que sirva como instrumento ou arma lançada por particulares ou grupos concretos: “[...] Deben crearse en él los presupuestos para la serenidad, el distanciamiento y la reserva (y, si es posible, también para el respeto de los derechos de los demás participantes [...]" (HASSEMER, 1984, p.169-170).

A Convenção Europeia de Direitos Humanos dispõe sobre o direito de todas as pessoas a um processo equitativo e público, examinado em um prazo razoável por um tribunal independente e imparcial, o qual decidirá, quer sobre a determinação dos direitos e obrigações de caráter civil das pessoas, quer sobre o fundamento de qualquer acusação em matéria penal dirigida contra elas. Não obstante, como estabelece a Corte Europeia de Direitos Humanos, a Convenção deve ser interpretada de forma a assegurar os direitos concretos e eficazes em oposição 'ao teórico e ilusório', de modo a se aplicar os direitos consagrados no artigo $6^{\circ}$, mormente aqueles destinados a garantir que "Qualquer pessoa acusada de uma infração será considerada presumidamente inocente enquanto a sua culpabilidade não tiver sido legalmente provada" (6. § 2) (EUROPEAN COURT OF HUMAN RIGHTS, 1950).

O Tribunal Europeu tem afirmado que o princípio da presunção de inocência não se limita a uma garantia procedimental em matéria penal: o seu alcance possui dimensão ampliada e exige que nenhum representante do Estado declare alguém culpado de uma infração antes que a sua culpabilidade tenha sido estabelecida por um tribunal. ${ }^{10}$

A Convenção Americana de Direitos Humanos (ORGANIZAÇÃO DOS ESTADOS AMERICANOS, 1969), ao ditar e incorporar os Direitos Civis e Políticos concernentes à comunidade interamericana, dispôs, nos arts. $7^{\circ}$ e $8^{\circ}$, garantias que delineiam o respeito concreto aos direitos fundamentais no âmbito penal e processual. Esse esforço empreendido para concentrar num mesmo estamento jurídico as premissas relativas à liberdade pessoal e as garantias judiciais foi benfazejo para o sistema de justiça criminal. As disposições normativas refletem os anseios e as necessidades jurídicas do continente interamericano.

No tocante ao Sistema Africano constituído pelos Estados-Partes, membros da Organização para a Unidade Africana, os direitos fundamentais expressamente reconhecidos e garantidos pelas demais Convenções Internacionais encontram guarida na Carta Africana de Direitos Humanos e dos Povos. E o postulado de maior envergadura para o processo penal assenta-se no art. $7^{\circ}$, no qual reafirma a importância de se promover um procedimento justo, de se garantir que toda e qualquer pessoa possa ter a sua causa apreciada. E essa garantia compreende: o direito de buscar amparo nos tribunais nacionais competentes de qualquer ato que viole as normas legais internas; assegurar a presunção de sua inocência até que a culpabilidade do sujeito seja estabelecida por um tribunal competente; o direito de ser julgado num prazo razoável por um tribunal imparcial (BRITTO, 2017, p. 167).

10 (Allenet de Ribemont c. France, 10 février 1995, $\S \S 35-36$, série A no 308p. 16, § 35). Quant au fond, la Cour rappelle que le principe de la présomption d'innocence ne se limite pas à une garantie procédurale en matière pénale : sa portée est plus étendue et exige qu'aucun représentant de l'Etat ne déclare qu'une personne est coupable d'une infraction avant que sa culpabilité ait été établie par un tribunal. 
Com efeito, também é necessário que a comunicação dentro do processo penal se revista de um discurso livre de dominação, a fim de que se extraia dele a verdade perseguida. Hassemer enfoca a questão sublinhando a exigência de que o processo penal se norteie de acordo com as ideias de compreensão e comunicação, da necessidade de que o Tribunal desça de seu pedestal e discuta e delibere de igual para igual com os demais participantes do processo. E essa verdade, diz Hassemer (1984, p. 163), surge mediante o discurso, o diálogo: “[...] Posibilitar y asegurar la comprensiónes cênica garantizando al tiempo los derechos de todos los intervinientes puede denominarse sintéticamente 'formalización' del processo [...]."

\section{PRÁXIS, PARALAXE E OS CASOS PENAIS}

Deslocando o objeto de estudo para a práxis, cada caso penal se desenvolve a partir de um procedimento criminal ou rito (comum, dividindo-se em ordinário, sumário, sumaríssimo ou os especiais). Uma série de atos coordenados, organizados e que objetivam a prestação jurisdicional. Esse procedimento que se teoriza no processo civil é, na concepção de Fazzalari, um procedimento em contraditório. No agir comunicativo habermasiano, os processos de entendimento também podem ser compreendidos como uma série encadeada de atos de fala, cuja finalidade é o consenso, que, por sua vez, deve satisfazer as condições de aceitação racional. Esta aceitação extraída da razão de cada personagem processual se concretiza no conteúdo de cada proferimento:

[...] Segue-se assim com a ideia de que o primeiro falante (ator processual), ao levantar uma pretensão de validade, somente terá sucesso na estrutura comunicacional se o segundo falante (ou demais participantes processuais) reconhecerem ou rejeitarem a pretensão do primeiro ator, sustentando suas teses ou decisões em algum tipo de razão ou argumento. Por isso, que se persegue aqui a via do agir comunicativo no campo do processo penal. E tais premissas devem ser - verdadeiramente - instaladas no ambiente da práxis jurídica. Sob o véu da via comunicativa não há espaço para subterfúgios; ou se proporciona acesso à fala e à discussão, ou não se proporciona [...] (BRITTO, 2014, p. 223).

A diferença entre a teoria e a prática pode ser observada nos meandros da cena jurídica. No dia a dia forense não é difícil achar quem conte uma história que remeta aos desalinhos da ritualística procedimental. Inobservância às "regras do jogo", desrespeito às normas e aos prazos, arbitrariedades e abusos. Se de um lado, reforçam-se as penas e os aparatos punitivos, de outro, as garantias do processo são reduzidas, conforme destaca Prado (2010, p. 189):

11 La exigencia de que el proceso penal se sigue las ideas de "comprensión y de comunicación”, de que el Tribunal baje de su pedestal y discuta y delibere de igual para igual junto a los demás participantes do proceso, son exigencias que no solo se corresponden con la tradición europea que viene desde el Siglo XVIII, sino que también se alimentan de una fuente moderna: la doctrina el discurso libre de dominación elaborada por la teoría crítica de la Escuela de Frankfurt". Dicha doctrina toma como punto de partida la idea de que la observación no son la verdad. No existe una teoría de la correspondencia sobre la verdad como ha estimado la ontología clásica y la teoría del conocimiento, en el entendido de que la verdad era la correspondencia correcta entre objeto y objeto del conocimiento: adequatio rei et intellectus. 
[...] São reduzidas as garantias do processo penal e endurecidas as regras de aplicação do direito penal material, incluindo aí, paradoxalmente, a flexibilização dos direitos fundamentais que regulam a incidência do direito punitivo em caráter excepcional e os limites do estritamente necessário. A concepção do agente do delito - e do suspeito de ser agente de delito - como inimigo social parece autorizar o emprego de todo tipo de recursos [...].

Inúmeras vezes as práxis cotidianas penais parecem ser diametralmente opostas à lei. É a paralaxe cognitiva que nos faz repensar sobre o sistema de administração da justiça criminal. Não é surpresa o fato de as condutas "do jeitinho" permanecerem como cifras ocultas diante do sistema legal, porque a conivência entre as pessoas envolvidas é fator considerável. O incremento diário de situações praticadas pelos representantes do Estado, em que juízes subscrevem falsamente declarações como prestadas em sua presença e às quais jamais estiveram presentes; promotores que assinam atas sem que tenham estado na audiência, assim como serventuários da justiça que certificam diariamente várias dessas falsidades ideológicas são exemplos producentes descritos por Zaffaroni (2000, p. 58) e que corroboraram com os argumentos até aqui declinados. A retenção dos autos do processo criminal, por tempo superior, pelo membro do Parquet, quando a lei estipula prazo (para a sua manifestação), também é um fator estimulante para um ambiente opressivo. Por outra vertente, e embora legalmente justificável, nem sempre o acusado pretende basear a sua defesa arguindo a prescrição, a fim de ver extinta a punibilidade, porque há outras questões e argumentos relevantes e necessários que devem ser expostos, e nem sempre são de conhecimento dos órgãos do Estado. Ainda nessa linha, o excesso de prazo de posse dos autos nas mãos de uma das partes, nos casos em que figure mais de um acusado, também contribui para desigualar a relação processual, tornando-se, portanto, arbitrária. Por esse motivo, a responsabilidade no cumprimento estrito e na fiscalização da lei processual de base constitucional é imprescindível, e isso não é favor; antes, porém, um dever. "[...] Dever de lealdade e responsabilidade dos representantes dos órgãos públicos para com a sociedade, fidelidade do juiz à lei penal. [...].” (BRITTO, 2014. p. 291).

O exame crítico desses fenômenos é necessário. É possível notar, por exemplo, posturas antidemocráticas de magistrados na condução dos depoimentos de testemunhas ou interrogatório do réu, procurando transformar suas percepções e impressões pessoais nas falas dos que ali estão para prestar esclarecimentos. A própria defesa técnica, ao se insurgir contra atitudes desse estilo, também passa a ser alvo de retaliações; quando não é surpreendida com "voz de prisão" por suposto desacato. E esse tipo de vilania acaba causando grave prejuízo para o acusado, a parte mais frágil dessa relação processual.

Os desajustes no sistema de administração da justiça podem ser observados também pelo uso utilitarista do direito penal por meio de cartazes e avisos afixados nas instituições públicas, os quais ameaçam de sanção aqueles que vierem a ofender ou desobedecer servidores e agentes públicos do Estado. Será que já não é tempo de retirar as comunicações ameaçadoras que se realizam com o uso da linguagem penal? Embora a norma penal seja considerada como um 
instrumento de comunicação, da forma como é empregada, ela não funciona como um mecanismo cognitivo de comunicação, pelo menos nos moldes informativos; não é uma forma exatamente de aconselhamento ou de troca. Neste caso, e em inúmeros outros, ela é voltada exclusivamente aos cidadãos comuns, cuja mensagem penal (Strafbotschaft) é alimentada por dois elementos instrumentais: a intimidação e o adestramento (HASSEMER, 2001, p. 1009-1011). Através da imposição da lei e de um código a ser aplicado e executado sobre o violador da norma penal, é que se exerce o convencimento. A mensagem é enviada na expectativa de que as pessoas cumpram as regras, se intimidem com elas e se mantenham exatamente de acordo com o "treinamento" recebido a partir da ameaça e da intimidação, e não exatamente que as conheçam, com elas concordem ou delas discordem.

Em facticidade e democracia, Habermas (2003, p. 249) não crê que a instrumentalização do processo transcorra de maneira exata ao que prescreve a lei, na medida em que o resultado de um processo pode ser explicado pelos interesses, socialização e pela pertença a determinadas camadas, além da estrutura e personalidade dos juízes por questões ideológicas e de poder ou por outros fatores dentro e fora do sistema jurídico. Nesse contexto, a prática de decisão já não é mais estabelecida internamente através de procedimentos do caso e do fundamento do direito, diz o filósofo.

Em relação às infrações de menor potencial ofensivo, de competência do juizado especial criminal, a denominada justiça consensual é producente e procura atender o apelo da resolução do conflito; mas, na realidade, essa prática pode ser bem perigosa, em razão do próprio mecanismo do sistema legal, que permite, automaticamente, a remessa de peças da polícia para a justiça criminal sem que ninguém, em regra, possa frear isso. Ademais, as formas empregadas em face do autor do fato para que aceite logo a proposta de transação penal não obedecem exatamente ao objetivo específico de pôr fim ao conflito ou buscar o consenso, mas são fincadas na "produtividade", na redução do espaço/custo financeiro de trabalho e nas estatísticas promissoras. Nessas infrações consideradas de baixa ofensividade, o ônus probandi, por parte do órgão acusador, também parece ser mera circunstância; em nome do princípio da celeridade, muitos fatos deixam de merecer suficiente investigação. Com isso, restringem-se direitos e a democracia perde espaço (BRITTO, 2014, p.189). Assim, não é de se estranhar que mecanismos de garantia presentes na legislação processual penal e na Constituição sejam rejeitados. Todos esses sintomas são fenômenos comuns, cotidianos, mas contrários à lógica do direito.

A observação feita por Klaus Günter (2004, p. 18) sobre o problema da responsabilidade pelo viés da teoria do discurso, embora limitada à problemática da imputação, pode ser aqui utilizada como reflexão e contexto da democracia atuante no sistema de justiça criminal. A ideia de "responsabilidade" como um conceito-chave ajuda a compreender as mudanças na sociedade moderna e assim a estender o modelo que deve ser assumido por todos os atores processuais. Pessoas representantes do Estado, investidas das atividades públicas, devem se conduzir e atuar de modo responsável e ético. Sob este prisma, para que se alcance a figura da defesa, é preciso que o passo da "responsabilidade" processual seja dado pelos representantes púbicos. 
[...] O Estado, investido do monopólio dos meios de coerção autorizados, se autolimita pelas garantias do devido processo e, por isso, e somente nessas circunstâncias, quer dizer, quando o processo está organizado de forma democrática, pode esperar lealdade de defesa. [...] (NASCIMENTO, 2011, p. 227).

Por todos esses aspectos, é de se afirmar que as máscaras e os rituais do passado se transmutam em vestes talares. O controle do poder penal, embora imperceptível para a maioria, se faz presente nitidamente, na proporção em que os mecanismos de proteção colocados à disposição dos indivíduos pela Constituinte de 1988 são violados. Isso acontece, muitas vezes, pela complacência de um judicialismo passivo diante dos abusos percebidos em âmbito processual, seja pela própria ação arbitrária e dominatória encoberta pela toga ou pela máscara do juiz “inquisidor”.

Ademais, a doutrina processualista penal vem, há tempos, respondendo com veemência à prática judicial na qual o magistrado permanece inquirindo as testemunhas no modelo inquisitivo, mesmo após a alteração do art. 212 do CPP. A eleição brasileira pelo modelo acusatório implica o afastamento da gerência e busca da prova penal pelo juiz. Em razão disso, diferentes juristas têm enfatizado que o processo será acusatório se a gestão da prova não couber ao juiz. ${ }^{12}$

[...]A produção da prova é tarefa desses sujeitos processuais. Não parece que a nova redação do art. 212 do CPP seja inconstitucional. Logo, se não for inconstitucional ou não estiver em antinomia com outro dispositivo que o afaste, parece razoável que se possa não apenas requerer, mas, sim, "exigir" que o Poder Judiciário aplique a lei processual, uma vez que o cidadão tem um direito fundamental a uma resposta adequada à Constituição [...] (STRECK; TRINDADE, 2010).

Dentre todos esses aspectos está entrelaçado outro ponto absolutamente significativo: muitos magistrados não se sentem obrigados a fundamentar suas decisões. Ainda há muita discussão, de variados matizes, em torno da exigência da fundamentação na decisão que recebe a inicial acusatória, por exemplo. Por outra vertente, alguns magistrados deixam de enfrentar argumentos levantados pela defesa técnica do réu. Em diferentes circunstâncias, os chamados "easy cases" são objetivados e simplificados por uma decisão "conforme a sua consciência", assegurada por

12 Por todos: "[...] Ocorre que, quando o juiz não sai à busca da prova - e nem deve sair! -, ao Ministério Público caberá fazer a prova da acusação, o que é o óbvio diante dos dispositivos constitucionais e - agora - do Código de Processo Penal (art. 212). [...] Desse modo, neste caminho rumo à concretização do sistema acusatório, o Ministério Público não pode restar inerte e permanecer confinado na mediocridade que o sistema inquisitorial lhe reservava, ou seja, de coadjuvante do juiz. Não importa, aqui, a vontade do legislador ou a sua intenção, discussão essa já superada há muito. O que importa é que ficou estabelecido que o juiz não pode mais inquirir as testemunhas nos moldes como vinha procedendo. Se assim o fizer, o processo é nulo! Chegou o momento de o Ministério Público e a advocacia dizerem a que vieram. A produção da prova é tarefa desses sujeitos processuais [...].”(STRECK; TRINDADE, 2010). 
uma espécie de "salvo conduto", que os desobrigaria dos discursos de fundamentação. Não sem razão são as reflexões de Streck, quando faz severas críticas ao dizer que, em plena vigência da Constituição de 1988, o próprio resultado do processo dependerá do que a consciência do juiz indicar, pois a gestão da prova não se dá por critérios intersubjetivos, devidamente filtrados e pelo devido processo legal, e sim pelo critério inquisitivo do julgador (STRECK, 2010a, p. 26).

A posição assumida por Streck certifica que é desarrazoado que os acusados fiquem à mercê da consciência dos juízes; o direito, diz o autor, não é (e não pode ser) aquilo que o intérprete quer que ele seja. Portanto, o direito não é aquilo que o Tribunal, no seu conjunto ou na individualidade de seus componentes, diz que é (STRECK, 2010a, p. 25).

\section{CONCLUSÃO}

O judiciário, como arquétipo da veste talar, sem as suas máscaras e rituais, parece ainda não ter descoberto inteiramente o sentido da democracia. Atores processuais, arrogando-se o papel de legisladores, ou travestindo-se de inquisidores à caça ao "herege", ou contentando-se com o figurino "talar" na persecutio ao "estranho", também incorrem em posturas incompatíveis com o modelo acusatório. A atitude passiva de muitos atores públicos do sistema de administração da justiça diante das irregularidades e abusos observados na tramitação dos feitos criminais desqualifica o Estado de Direito e compromete a confiabilidade das instituições públicas. A crise de confiança que abarca os diferentes Poderes no Brasil tece a sua teia exatamente na falha ética dos atores públicos em relação aos papéis que desempenham. Por isso, as reflexões teóricas precisam passar para o plano da efetividade dos direitos e garantias constitucionais jungidos na busca de um procedimento criminal justo. Essa perspectiva do direito ao processo equitativo plasmada pelo fenômeno da linguagem é a gênese da democracia. A obtenção desse grau de justeza procedimental só alcançará níveis aceitáveis se a linguagem agir; se a proposta do argumento e contra-argumento, numa posição dialógica do processo, puder ir à frente. Canotilho (1998), ao declinar que procedimento justo é aquele que tende a "densificar-se como procedimento comunicativamente justo", aponta para a órbita da força do argumento e dos mecanismos do diálogo. A centralidade do pensamento está fincada na necessidade inadiável de se descortinar a via do diálogo como forma de proporcionar um procedimento justo.

Por certo, as digressões levantadas no presente artigo não se esvaem nestas linhas, porque o assunto ainda demanda discussão. Há muitos sorvedouros que precisam ser pensados e repensados, sobretudo na construção de uma teoria do processo penal que dê conta de responder a todos esses anseios. Entretanto, não é desarrazoado enfatizar que a Constituição brasileira deve ser interpretada de forma a assegurar os direitos concretos e eficazes consagrados no art. $5^{\circ}$, em oposição 'ao teórico e ilusório'. Numa concepção mais arejada contemporaneamente, processo justo (fair trial) é aquele que se estabelece ou se incorpora com supedâneo comunicacional. Seguese assim que a perspectiva dessa busca pelo processo justo estreita íntima relação com a forma dialogal, motivo pelo qual as engrenagens do sistema e os atores jurídicos precisam operar nesse 
sentido.

\section{REFERÊNCIAS}

BAL, Peter. Discourse ethics and human rights in criminal procedure. In: HABERMAS, Jürgen. Modernity and law. London: Mathieu Deflen, 1996. p. 71-100.

BRITTO, Cláudia Aguiar Silva. O direito à assistência criminal nos países lusófonos. In: ROCHA, Maria Elizabeth; COSTA, Marli M. Moraes da; HERNANY, Ricardo (org.). O alcance dos direitos humanos nos estados lusófonos. Santa Cruz do Sul: EDUNISC, 2017. p. 158-179.

BRITTO, Cláudia Aguiar Silva. Processo penal comunicativo: comunicação processual à luz da filosofia de Jürgen Habermas. Curitiba: Juruá. 2014.

CAMPBELL, Kathryn; DENOV, Myriam. Erreurs judiciaires: les répercussions d'un emprisonnement injustifié. Juste Recherche, Ottawa, n. 13, 2012.

CANADA. Ministère de la Justice. Erreurs judiciaires: les répercussions d'un emprisonnement injustifié. 2015. Disponível em: http://www.justice.gc.ca/fra/pr-rp/jr/jr13/p5a.html. Acesso em: 15 set. 2018.

CANOTILHO, José Joaquim Gomes. Direito constitucional e teoria da constituição. Coimbra: Almedina, 1998.

CONSEIL SUPÉRIEUR DE LA MAGISTRATURE. Les français et leur justice. Restaurer la confiance. Paris: ConseilSupérieur de La Magistrature, 2008.

DUSSEL, Enrique. Ética da libertação: na idade da globalização e da exclusão. Tradução de Ephraim Ferreira Alves, Jaime A. Clasen e Lúcia M. E. Orth. 4. ed. Petrópolis: Vozes, 2012.

EUROPEAN COURT OF HUMAN RIGHTS. Convenção Europeia de direitos humanos. Council of Europe F-67075 Strasbourg cedex. 1950. Disponível em: www.echr.coe.int. Acesso em: 28 dez. 2018.

FRANCA, Geminiano. A imprensa e a lei. Rio de Janeiro: C. B. F., Jur. Bras. 1936.

GARAPON, Antoine. Bien juger. Essai sur le rituel judiciaire. Paris: Odile Jacob, 2001.

GARAPON, Antoine. Le gardien des promesses: justice et démocracie. Paris: Odile Jacob, 1996.

GARCIA AMADO, Juan Antonio. La filosofia del derecho de Habermas e Luhman. Bogotá: University Externado de Colombia, 2003.

GÜNTER, Klaus (org.). Teoria da responsabilidade no estado de democrático de direito. Rio de Janeiro. Saraiva. 2004. 
HABERMAS, Jürgen. A ética da discussão e a questão da verdade. Tradução de Marcelo Brandão Cipolla. São Paulo: Martins Fontes, 2007b.

HABERMAS, Jürgen. A inclusão do outro: estudo de teoria política. 3. ed. São Paulo: Loyola, 2007a.

HABERMAS, Jürgen: Direito e democracia entre facticidade e validade. Tradução de Flávio Siebeneicher. 2. ed. Rio de Janeiro: BTU, 2010. v. I.

HASSEMER, Winfried. Das Symbolische am symbolischen Straf recht. In: SCHÜNEMANN Bernd et al. Festschrift für Claus Roxin.Zun 70. Berlin; New York: Walter de Gruyter, 2001. p. 1001-1020.

HASSEMER, Winfried. Fundamentos del derecho penal. Buenos Aires: Bosch, 1984.

HASSEMER, Winfried. Introdução aos fundamentos do direito penal. Tradução de Pablo Rodrigo Alflen da Silva. 2. ed. Porto Alegre: Sérgio Antônio Fabris: 2005. Título original: Einführung in die Grundlagen des Strafrechts.

MAUSS, Marcel: Sociologia e antropologia. São Paulo: Cosac Naify, 2007.

MELO, João Ozorio de. Estudo mostra porque inocentes são condenados à prisão. Boletim Notícias Conjur, São Paulo, 16 fev. 2014. Disponível em: https://www.conjur.com.br/2014fev-16/estudo-mostra-porque-tantos-inocentes-sao-condenados-prisao-eua. Acesso em: 24 jan. 2018.

NASCIMENTO, Rogério José Bento Soares. Contribuindo para uma doutrina constitucional adequada: dialogando com a teoria da constituição dirigente. Juris Poiesis, Rio de Janeiro, v. 8, n. 8, p. 421-437, 2005.

NASCIMENTO, Rogério José Bento Soares. Lealdade processual. Rio de Janeiro: Lumen Juris, 2011.

NATIONAL REGISTRY OF EXONERATIONS. Exonerations in 2013: The National Registry of Exonerations. 4 Feb. 2014. Disponível em : http://www.law.umich.edu/special/exoneration/ Documents/Exonerations_in_2013_Report. Acesso em: 4 abr. 2018.

OLIVEIRA, Marcelo Andrade Cattoni. A teoria discursiva no debate constitucional brasileiro. Disponível em: http://www.mundojuridico.adv.br. Acesso em: 4 abr. 2018.

ORGANIZAÇÃO DOS ESTADOS AMERICANOS. Convenção Americana de Direitos Humanos. 1969. Disponível em: https://www.cidh.oas.org/basicos/portugues/c.convencao_ americana.htm. Acesso em: 28 dez. 2018.

PRADO, Geraldo. Em torno da jurisdição. Rio de Janeiro: Lumen Juris, 2010. 
STRECK, Lênio. O que é isto: decido conforme minha consciência? 2. ed. Porto Alegre:

Livraria do Advogado. 2010a.

STRECK, Lênio. Verdade e consenso. Constituição, hermenêutica e teorias discursivas.

Da possibilidade à necessidade de respostas corretas em direito. Porto Alegre: Livraria do Advogado, 2010b.

STRECK, Lênio; TRINDADE, André Karam. Produção de prova cabe ao MP e à defesa. 2010. Disponível em: https://www.conjur.com.br/2010-jan-11/producao-prova-processo-penal-cabe-mp-defesa?pagina=6. Acesso em: 10 maio 2018.

ZAFFARONI, Manual de direito penal brasileiro: parte geral. 5. ed. São Paulo: Revista dos Tribunais, 2000.

Como citar: BRITTO, Cláudia Aguiar Silva. Dos totens às vestes talares: os atores processuais (des)conhecem o que é democracia?. Revista do Direito Público, Londrina, v. 15, n. 1, p. 174192, abr. 2020. DOI: 10.5433/24157-108104-1.2020v15n1p. 174. ISSN: 1980-511X

Recebido em: 28.01.2019

Aprovado em: 17.02.2020 